\title{
Void. Interstitial practices of doubt and reward
}

\author{
Marieluise Jonas and Heike Rahmann
}

\begin{abstract}
As products of urban growth and decline, urban voids are spaces in transition from one stage of development to another. Their interstitial existence portrays a non-classifiable resistance and freedom to social and ecological conventions of the city.
\end{abstract}

This paper outlines our practice and approaches to working with the natures of urban vacant spaces in the context of growth and transformation in two cities with distinct socio-economic and cultural drivers that are mirrored in urban form and fabric: Tokyo and Melbourne.

Our practice in working with urban voids through mapping, design interventions, design strategies, virtual agency and writing are discussed alongside topics of appropriation, informality, design strategies and ecological processes. We argue that urban voids can serve as testing grounds for an idea of dynamic urbanism and a context-driven design practice in landscape architecture.

We also continue to negotiate our roles as landscape architects in relation to questions of program and the value of the role of design in the activation of these voids. Hence the positioning of our practice as an interstitial one where both doubt and reward are the outcomes.

In our view urban voids hold a promise: they offer a capacity to contribute to urban design strategies, and form urban ecosystems; and they operate as catalysts for creative practices if - as we argue in this paper - they are recognised and utilised in a practice that is context-based.

We discuss urban voids through two focus areas in our research: Melbourne and Tokyo. In both cities, void spaces are situated in a context of transformation and growth. This paper sets out to describe our research practice over the past ten years and to illustrate how this specific condition of the 'urban void' within these two cities has led to developing approaches and methods that include a wide range of responses, their failures and successes.

\section{Urban Voids and Urban Transformation - defining the ground}

The twenty-first century is the urban age: in 1900, only ten per cent of the world's population lived in cities while, in 2007, the urban population increased to 50 per cent. By 2050, 75 per cent of the world's population is expected to live in cities (Burdett \& Sudjic 2007). Urbanisation is rapidly transforming Asia, where 17 of the world's 25 largest urban agglomerations can be found (AECOM 
2010). The trend in rapid urban growth can also be seen in Australia, where Melbourne, as one of the most rapidly growing capital cities in 2009-2010, recorded a population growth of 79,000 people, approximating a population increase of over 1,500 people each week (Australian Bureau of Statistics 2011). This accelerated growth poses immense challenges to the development of sustainable urban environments: securing clean air and water resources, preserving cultural heritage as well as the provision of open green space, and maintaining social balance and equality in publicly accessible spaces. While developing urban regions face severe infrastructural challenges, industrialised metropolises suffer the loss of cultural heritage, social disintegration as well as consumption- and emission-related problems in the rapidly changing urban environments. Facing these challenges, an urban agenda has been called for that matches the pace and intensity of the urban age.

On the other hand, urban transformation processes produce temporary urban voids: Spaces in transition from one stage of development to another. These spaces possess a capacity to counter perspectives on homogenised urban landscapes, to contribute to sustainable regeneration and growth. Yet temporary vacant spaces are not understood well enough in these capacities. In addition, the dynamic processes of transformation, which produce these spaces, are viewed as an obstruction rather than an opportunity in urban development to take vacant spaces into account. For example, recent European (Overmeyer 2002; 2007; Müller, Schmitt \& Selle 2003) and North American discourse (Oswalt 2005; Berger 2006; Gissen 2009) in relation to urban voids and their relative socio-economic and cultural context remains largely focused on and nuanced by conditions of urban decline.

In the mid-1990s the Catalan architect, writer and philosopher Ignasi De SolàMorales ignited discussion in relation to these spaces through a phenomenological reading of voids as expressions of strangeness, coining the term 'terrain vague'. These vague spaces are vacant, unkempt, unused with no defined function, between stages of formal development and sometimes indefinitely waiting for future use. Even though these non-places have been eroded or closed down and are caught in a state of uncertainty, however, they may possess potential as the vagueness of the spaces' availability and function limits their attractiveness for formal planning, design and development processes. The traditional identification of urban space by status - legal, economical and functional - is challenged by this complex ambiguity of vagueness.

This relationship between the urban fabric and socio-economic as well as cultural context that is being exemplified in the research we have undertaken in Japan and Australia is one where conditions are determined by growth rather than shrinkage and this leads to questioning the causal relationship between voids and decline. It also suggests and invokes considerations of a dynamic urbanism.

Intertwined with buildings in the urban structure, voids are ubiquitous and form an integral part of a landscape of constant renewal. Urban voids are inseparably 
connected to the organic structure of becoming, maturation and decay: bleak illogical emptiness, colonised by patches of spontaneous vegetation, rainwater collecting on an abandoned pavement, reflecting the humming air-conditioning units. They can be read as transmitters of the ephemeral; as transient spaces that often serve no productive purpose, other than carparking. They offer the possibility of accidental discoveries and non-productive activities, experiences which are unplanned and momentary. They offer, maybe, just a glimpse of the unfinished.

In considering the contextual and cultural dimensions of urban void spaces, the concept of a dynamic urbanism emerges. How might this might be defined? What might be potential alternative scenarios of critical spatial practice for both a large urban scale and an immediate small-scale context?

\section{Opportunity}

If we consider void spaces in our compendium of urban sites, there is a need to search for a new paradigm of functions, occupation and activity; there might even be the potential for these small spaces to induce their very own typology.

Through our practice, we speculate that small urban voids offer the potential of forming networks of interconnected spaces that have the capacity to offer sequential, simultaneous and diverse types of uses or levels of interaction. These small spaces are often found randomly and dispersed in the urban fabric. This condition creates small spaces in close proximity to residences and other types of urban infrastructure. This occurs in areas that are faced with an increased demand for open space and variability in form, size and nature. We can further speculate on the possibility of a network of spaces that combine the practice of informal or creative uses, widely in place in Australian cities, with the necessity to address the lack of open and green space and a perspective of the incomplete. In this context, ownership and stewardship become relevant considerations. Melbourne, for example, has a number of sites that exemplify how an alliance between owners and creative appropriation is framing the potential of an active use. In Tokyo, on the other hand, formal and informal practices play out differently.

In this paper we reflect on our ongoing practice as a critical spatial practice working with urban voids through projects and investigations that we have undertaken between 2001 and 2012. In this we show how the subject matter has informed the methodology of our research - involving failures and achievements, doubt and reward - and is now beginning to inform a specific context-driven idea of dynamic urbanism. 

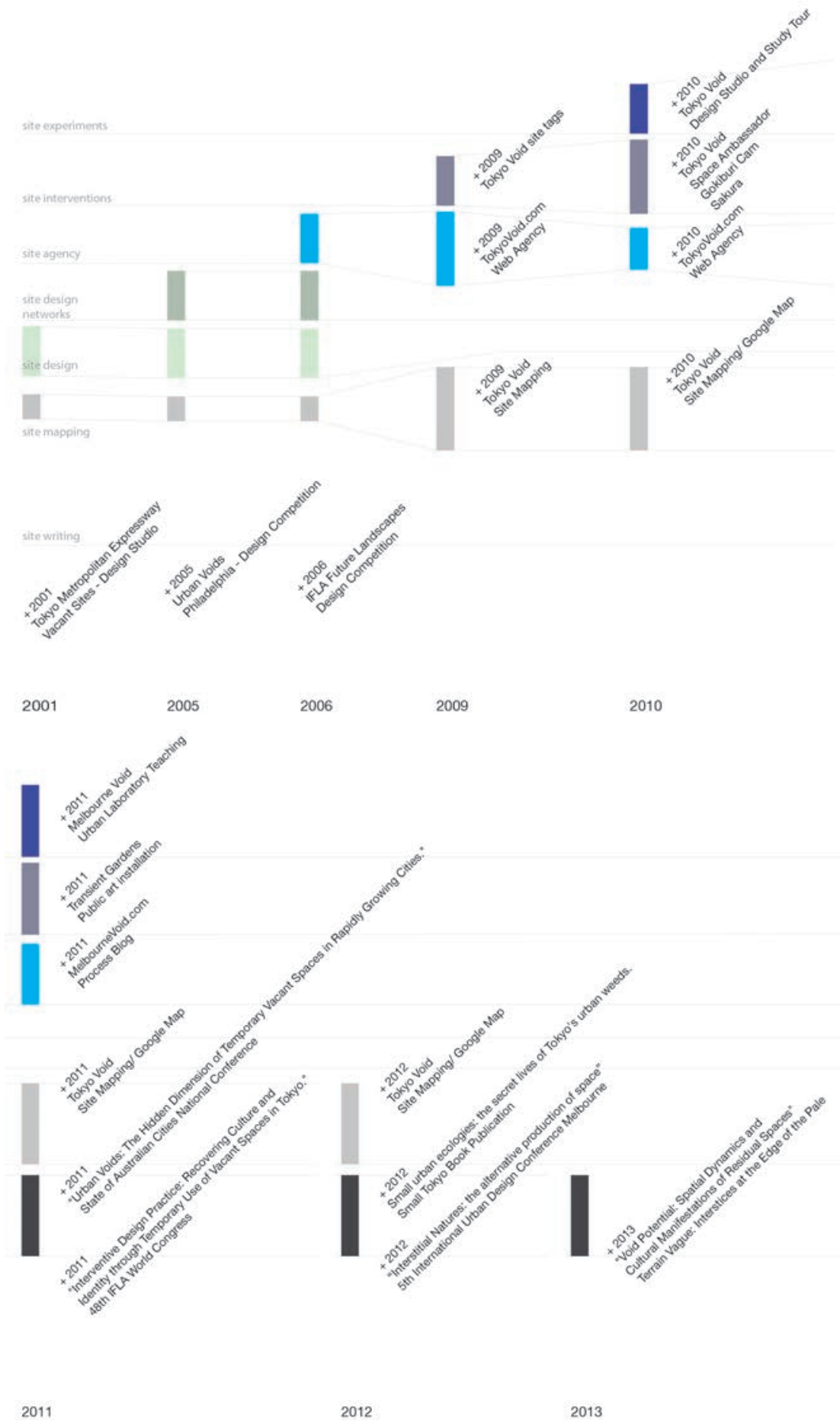

Figure 1. Urban Void: negotiating between Tokyo and Melbourne, practice and research. 
Figure 1 positions the projects we have undertaken on a timeline and draws out the methodology and shifts in how we approached the thematic of urban voids.

Starting out in 2001, with what we now understand as an implicitly European view of Tokyo's small voids, we worked to activate these spaces using a traditional understanding of site design. Making the spaces accessible and furnishing them was an early approach in designing a series of spaces adjacent to the Tokyo Metropolitan expressway in Setagaya-ku in Tokyo.

Through this first project we moved on, in a second design project, to evaluate the capacity for these spaces to form networks. We speculated that if the spaces were to be seen as a collective, they could change individually while the overall network of voids would remain a resource for active use by locals. With this understanding we developed the idea of a space agency that would sit in between the owners of the sites and the users and would manage the uses of spaces as they became available.

In the following sections we expand on the projects in Tokyo and Melbourne to discuss our practice and its research into, and negotiation with, the conditions of 'the urban void'.

\section{Tokyo Void}

Tokyo, synonymous with extreme urban density and lack of green space, together with a cultural practice of strict maintenance regimes, produces very few spaces of vegetation, even fewer of remnant or quasi-natural weed vegetation. Tokyo's 14.6 million inhabitants have access to less than five square metres of open space per capita on average (Tokyo Metropolitan Government 2011). In 2011 the total number of parks, urban plazas, gardens and other open space in Tokyo amounted to 6.3 per cent of the total city area. In comparison, New York recorded 24 per cent of open green space in the same study. This figure includes most vegetation such as street trees and vegetated river embankments, cemeteries, shrines and temples and agricultural land. The average plot size in Tokyo of 150 square metres for a single facility dwelling reduces private gardens to centimetre wide strips of vegetation - if they exist at all. Informal roadside flowerpot gardens form the only green spaces in many parts of the city.

In this context, urban voids are valuable spatial resources. The activation of temporary urban void spaces, currently 3.1 per cent of Tokyo's urban area, has the potential to immediately increase the total amount of open space by 50 per cent (Tokyo Metropolitan Government 2011: Urban Land Use Statistics).

Tokyo's Urban Land Use Statistics classify open space as non-built-up areas, such as parks, gardens, bodies of water, forest and agricultural land. This figure has been stable at around 2.9 - 3.1 per cent over the past 20 years. Utilising existing and available land - urban voids - offers the possibility of creating a flexible network of small and large open spaces that accommodates a range 
of uses and functions, including public open space, disaster prevention for earthquakes, natural habitat functions, energy production, recreation or event spaces.

The Tokyo Void research project (ongoing) started out to investigate utilisation strategies for vacant spaces, particularly in light of Tokyo's specific urban conditions, including issues of density, rapid transformation and urban growth. Throughout the project we have explored various appropriation strategies, such as on site occupations, and installations (i.e., formality, informality and hybrid forms of appropriation), we have tested their interrelation with various forms of ownership, levels of engagement and responsibilities. One of the key ambitions of the Tokyo Void project is to ascertain the distinct qualities of the typologies of temporary vacant spaces, while considering the distinct morphological and temporal qualities of the temporary vacant urban spaces in development and design. Understanding what the functions that urban voids possess is a vital to their activation.

\section{Observations - between the virtual and the real}

Five areas in Tokyo were selected as case studies, covering a wide range of neighbourhoods with distinctive demographic, economic and spatial configuration. The areas included Yanaka (historic district marked by recent gentrification), Ginza (central, high-class retail district), Komaba (residential district), Jujo (district of post-World War II rapid urban growth) and Odaiba/ Toyosu (district of land reclamation and urban renewal). Since 2009, we have mapped and revisited the Tokyo voids in yearly intervals in each of the case study areas. Through the mapping we found that approximately 85-90 per cent of the voids remain vacant for several years. Many vacant lots function as informal car parking space and often support a distinct type of vegetation of low grass and moss in damp areas. Other vacant lots are hidden behind construction fences and remain inaccessible to the public. Their sizes vary between a few square meters to large tracts of land in halted urban redevelopment schemes, such as the artificial island of Odaiba. Only a few construction developments take place while some vacant lots are transformed into coin-operated parking spaces.

As part of the project, we seek to make this information available to potential users of the sites through the tokyovoid.com website. There, potential users are able to see the pool of available sites in their neighbourhood. One of the key challenges, however, has been to facilitate this link between owner and potential user of the sites. 

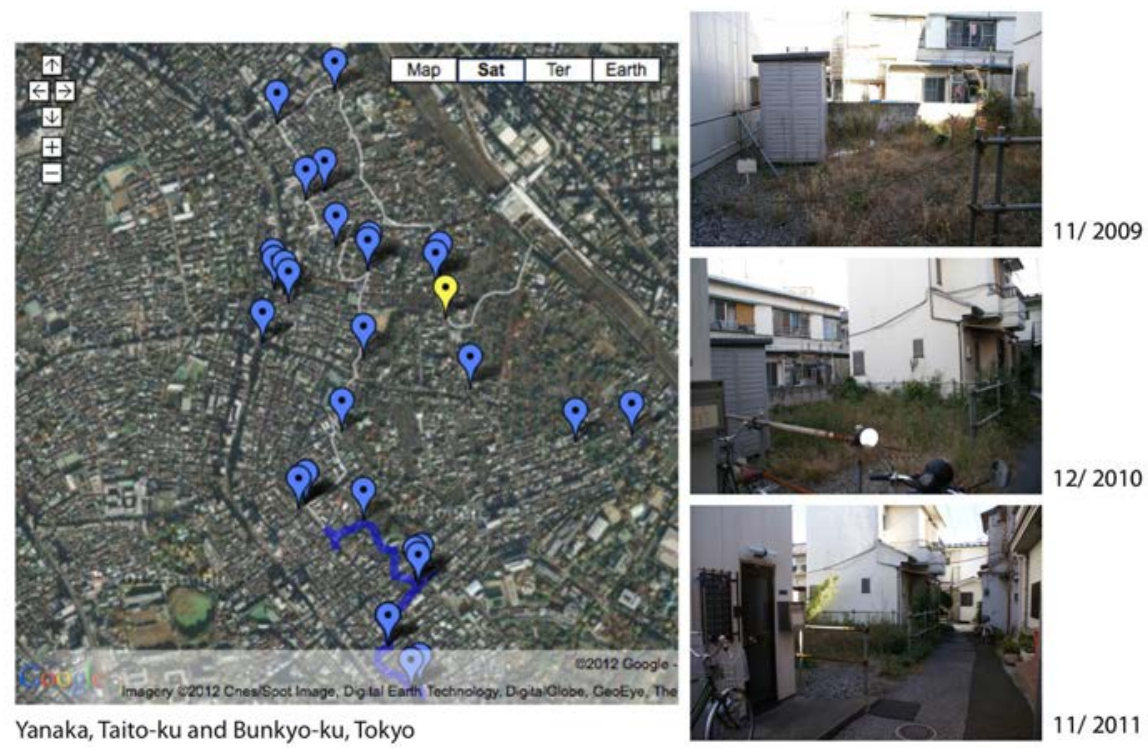

Figure 2. Mapping vacant spaces in Tokyo, 2009-ongoing.

Photography: The authors

In order to test a suitable link between owner and potential user, we have conducted urban interventions using digital technology. The concept involved designing and distributing labels across a number of vacant sites. Each label carried a Quick Response Code (QR code) that can be scanned and decoded through smartphone technology, linking to the project website. The tagging involved two interventions with individual strategies and a design process.

The first intervention concentrated on the tagging of void spaces that were already recorded in our previous mapping. This strategy was intended to initiate discussions about those sites by bringing owners, potential users and other interested people to the web platform. As the intervention was conducted in spring, the Sakura (cherry flower) was selected as a suitable shape for the markers while various materials (e.g., MDF, plexiglass) and production processes (e.g., laser cutting, engraving) had to be tested for their performative qualities in the field in relation to durability and legibility of the tags. 

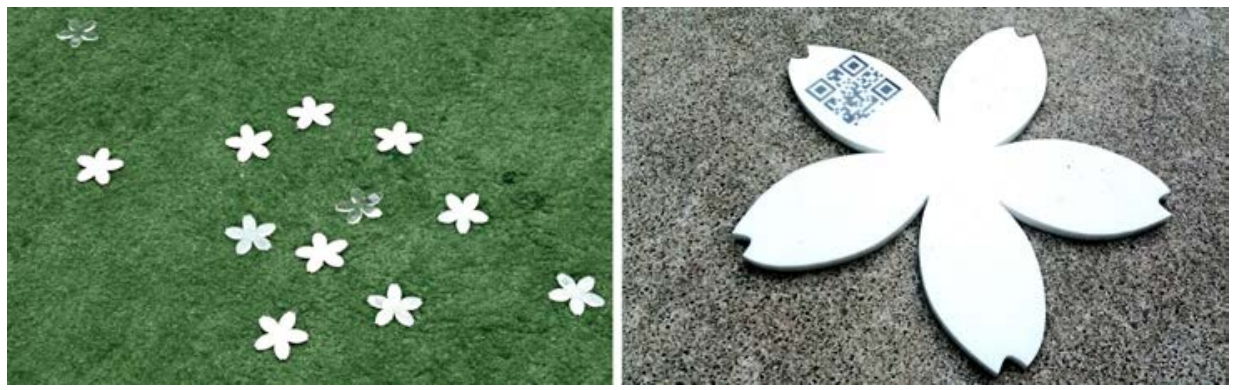

3a. Testing of Sakura tags, 2010.
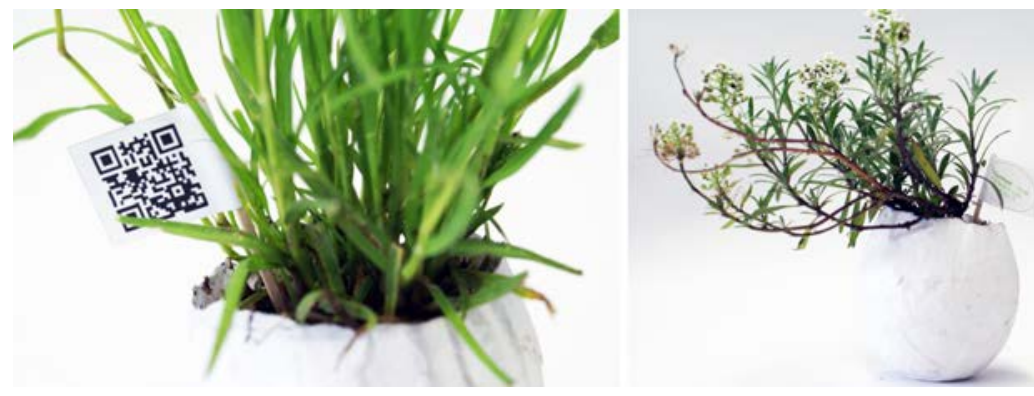

3b. Space Ambassador, 2010.

Figure $3 a$ and $3 b$. The tagging interventions encourage the public to participate in the mapping of void spaces.

Photography: The authors

The second intervention - Space Ambassador - focused on engaging the public in the process of mapping new vacant sites and thus testing spatial connectivity, networks and interrelations of temporary vacant spaces. The Space Ambassadors are a series of markers, consisting of small plant containers that connect three vacant sites in Tokyo. First, plant material is collected from a neglected vacant space - some weeds are removed from the site and are replanted into small, custom-made containers. Each container forms a unique assemblage in which the plant is decontextualised from its former situation. New associations are created as they transform into almost domesticised artefacts: while the plants previously represented the marginalised existence of weeds, the flowerpots convert each plant into an individual specimen. Secondly, each flowerpot is equipped with a small flag inscribed with a QR code that contains information, a link to the tokyovoid.com website and instructions for an audience to participate in the next steps of this project. The containers are then taken to a new vacant space in a lively neighbourhood in Tokyo's historic district. As this new site is largely free from vegetation, the Space Ambassadors transform the site temporarily into a weed installation to attract engagement with the public. In the last step, the Space Ambassadors are used as new markers and catalysts for spatial and social interaction. People are encouraged to take the flowerpots and to transport the plants to a vacant space that they have identified in their 
communities. Since each plant becomes a marker for a new site, a multitude of new places that spread across the entire city will be identified. While the location and condition of the new site is initially only known to the person carrying the marker there, the carrier can upload the geospatial data to the project website through accessing the QR code. Thus, the technology allows us to reveal the exact locations of individual vacant spaces across the city while simultaneously outlining interconnections and larger networks of spaces.

Unfortunately, no interactive response was generated through these mapping interventions. While testing the material, the size and the shape of the Sakura tags, we paid attention to the craft quality of the objects, so that they would not be seen as an act of vandalism. It is possible that the tags did not contrast sufficiently with the surrounding conditions in order to invite attention. The interrelation between the site location and the selection of communication devices play a significant role in engaging the public with this intervention: the dependence on mobile technology in neighbourhoods with predominantly elderly populations also may have resulted in a low response rate.

In contrast, the Space Ambassadors attracted attention from passers-by, who were intrigued by the fragility and cuteness of the objects. The plants, although classified as weeds in their natural context, were presented in a unique format that resembled spatial and material qualities that can be found in Ikebana (traditional Japanese flower arrangement) and thus resonated well with the public. In addition, the white of the plant containers was in stark contrast with the dirt and gravel cover of the site on which they stood and, therefore, they attracted attention. Despite appreciation of the marker's visual appearance, the public participation in the project was different than originally anticipated. Instead of taking a flowerpot and volunteering to place the marker into a new vacant site, people offered to buy the Space Ambassadors, and would resist taking the plants if they were not for sale. While people who did engage with the vessels developed specific cultural code words and phrases for this project to reflect the appreciation of smallness (i.e., kai-haku-tan-sho) and cuteness (i.e. saiku ), we can retrospectively say that it was this quality of a perceived cuteness and fragility of the flowerpots that compromised the success of this intervention. Responses and inquiries received through the website were mainly generated through other web-based platforms and unrelated to the onsite spatial interventions. In addition, the inquiries came mainly from foreign residents of Tokyo, which suggests a further cultural divide in engaging with and speculating creatively about appropriation strategies for urban vacant spaces. New avenues emerged from the mapping approaches, however, and have been since developed in more depth.

\section{Appropriation - between designing, material and community engagement}

Through the mapping process we uncovered localised approaches that pragmatically use vacant spaces for the benefit of the community. Situated in 
the quiet area of Yanaka in Taito ward, the case of Kasu Harappa ONDI (lit. rental vacant space ONDI) is one example of a community-driven intervention. While the owners were undecided what to do with the site, they deliberately dismissed the opportunity to transform it into a financially lucrative car parking space. Instead, they decided to contribute to the creative atmosphere in the neighbourhood by providing an outdoor gallery space that local artists, performers and other creative people could rent for events and exhibitions. Although the concept of a gallery space perfectly fits into Yanaka's character, ONDI is anything but an ordinary gallery. Only a few simple rules outline the terms of use, enabling prospective users to take responsibility for their event while also providing maximum freedom as to how the space can be used. This offers the possibility for a diverse mix of events, ranging from performances, demonstrations, art exhibitions, and cultural celebrations to market events and student workshops. The idea behind ONDI is to provide a space that supports conversation and invites everyone to participate. The site transforms into an open stage, without walls and roof, exposed to the elements. The street turns into a theatre where strolling residents and visitors become part of the audience - participants in the event, not just spectators.
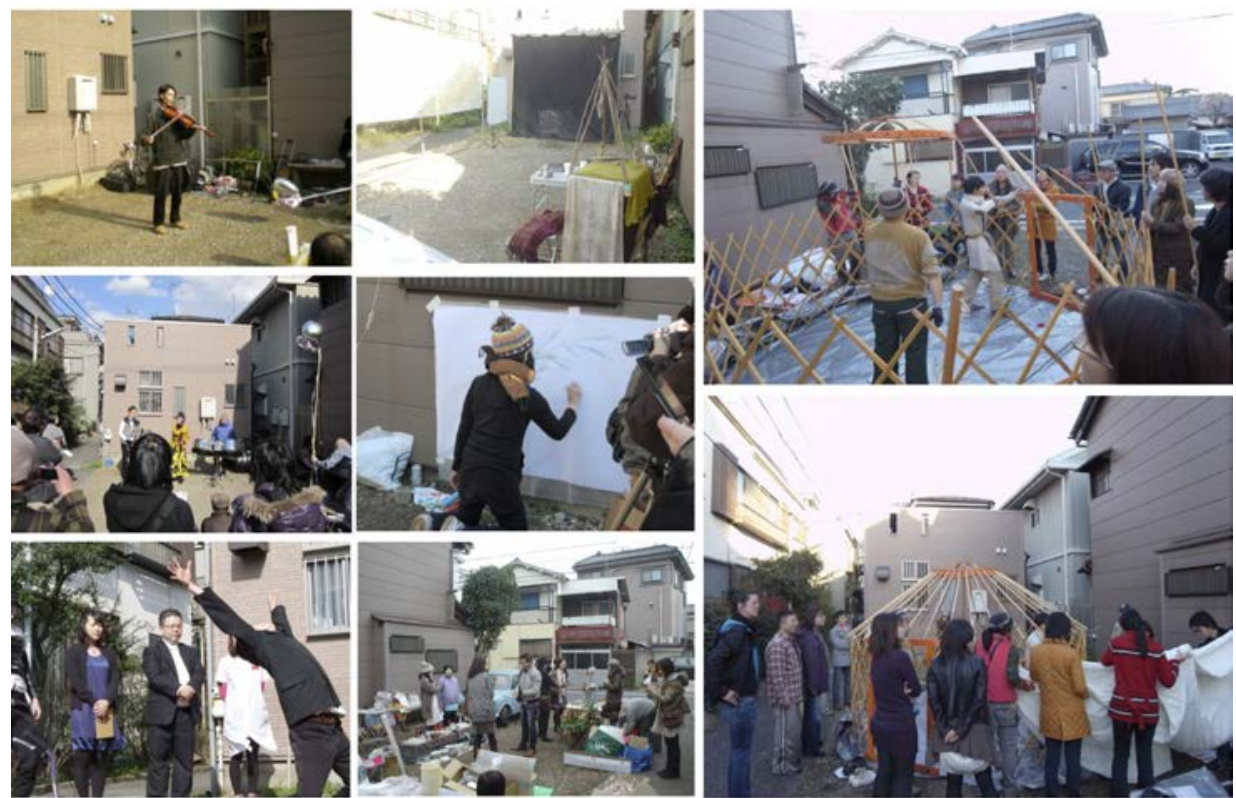

Figure 4. A vacant space turned into a participatory outdoor gallery, Kasu Harappa ONDI in Yanaka, Tokyo.

Photography: The authors

In addition to its unconventional conceptual framework, ONDI opens discussion about the physical qualities of Tokyo's vacant spaces. The name Kasu Harappa 
ONDI plays with the association surrounding the word harappa (literally, a vacant area and a word often used as a nostalgic reference to childhood, such as play that involved roaming the unused spaces of the city); here the word is used to signify a space for appropriation, full of potential, and nostalgic childhood memories. The word ONDI (音地), meaning sound of soil, reflects the beauty of the site, exposed to the natural elements. It is precisely this quality of depth and openness in the unsealed surface that offers real momentum for unpredictable, serendipitous activity in Tokyo, a city dominated by concrete and asphalt.

Since ONDI's inception in 2006, the number of activities on the site has increased significantly. The popularity of ONDI is reflected both in the increasing number of hosted events and in the increasing interest among ordinary Tokyoites, showing the immense potential of this alternative concept for inspiring creative action and bringing people together.

\section{Provocations - linking site and potential}

Taking the opportunity and freedom that ONDI offered for new ways of working with and thinking about void spaces, the site became for us a testing ground for appropriation strategies. While addressing the spatial and temporal conditions of the site, our interventions raised questions about larger urban issues, specifically neighbourhood engagement and responsibilities of the designer.

In 2010 a group of students worked with ONDI to test design interventions for urban voids on-site as part of an RMIT University design studio in landscape architecture. Student design responses ranged from projections and abstract physical tests to concrete programmatic designs. At a final exhibition on the site, Japanese landscape architecture practitioners were invited to discuss with the students their views on the potential of urban voids. The specific experience of an on-site intervention triggered varied responses between professionals and residents, who disapproved the activities on site, which in their view disrupted the quietness of the neighbourhood. Yet, local design professionals, architects and landscape architects, as well as members of the creative community in Yanaka, responded positively, as evidenced by the increased use of the site and greater recognition of the project.

Sakura - a poetic provocation. This intervention utilised associative narratives and played with the material quality, the meaning, and the appropriation of vacant sites. The sakura was selected as an overarching theme for the 2010 site interventions of which the use of cherry blossom petals was one part and the cherry blossom-shaped site tags formed another part. Conducted in spring 2010, the intervention covered the ONDI site that normally exposed the barren, naked ground and gravel surface with a thin veil of fragile and soft cherry blossom petals, moving in the wind. The act of covering attempted draw the focus to the site via a micro cosmos of leaves, rocks, and flowers, to internalise the site and to give it its own infinity. 
The cherry blossom petals were gathered from the nearby Yanaka Cemetery, one of the most popular places in Tokyo for Hanami (lit. flower viewing). The petals were dispersed over the vacant site and they remained for a few days. Hanami celebrates the ephemerality and transientness of life, symbolised through the fragility of the cherry flower. Blooming for only one to two weeks each year, the aspect of the blossom that is regarded as the most beautiful is when the petals fall and disperse with the wind.
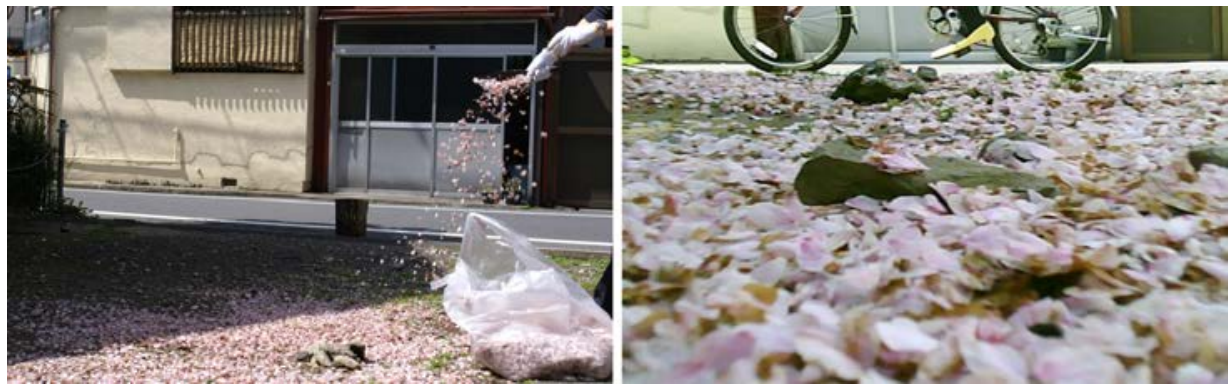

Figure 5. Sakura - a provocation, ONDI space in Yanaka, Tokyo, 2010.

Photography: The authors

Playing with the poetic notion of the cherry blossoms, the pink carpet transformed the barren site and attracted positive attention from passers-by and the wider community. The blurring of the site's boundaries, the drifting of flowers, the dirt, the ephemeral notions of the cherry blossoms can be read as metaphors for how we choose to view voids. It seems that if a strict boundary of program, a temporal situation, is drawn around a site, then the definition of opportunity in voids becomes limited.

The reaction of immediate neighbours, however, was not as appreciative. The installation was dismissed as problematic, because the cherry blossom petals that were dispersed by the wind were seen as dirt that had to be cleaned up. In working with what we view as the potential of vacant spaces, it is necessary to understand the blurring of meaning and boundaries, as well as messiness and the material quality as parts of appropriation processes. The questions that arose for us from this experience include: if neighbours are not the actors, who is? What conflicts are likely to arise and how can they be managed productively to enable the realisation of potentials?

\section{Melbourne Void}

Obviously, many of the observations and findings outlined above are grounded in Tokyo's unique cultural and spatial circumstances, and thus cannot be transferred to any other urban context. The Tokyo Void project does, however, allow us to reflect on the potential and relevance of vacancy in the context of broader urban issues, such as population growth, urban transformation, and 
scarcity of space. As outlined above, Melbourne faces increasing challenges to provide accessible open and green urban space in the future. In this environment, vacant spaces may become a viable spatial resource, similar to the condition in Tokyo. Concurrently, unique possibilities for the research emerge in Melbourne. Initial ideas for the Melbourne Void project were developed over 2010-2011, at a time when the quest for appropriation strategies in Tokyo was less rewarding.

The first opportunity that arose in Melbourne was the accessibility of vacant spaces in prime real estate locations and the approachability of landowners. A paradox in this city is that, despite Melbourne's rapid urban growth, inner-city development sites remain vacant for a long period of time, often for several decades, which creates a strong visual presence of vacant sites in prominent CBD locations. As development proposals are boldly advertised on billboards and hoardings, landownership and contact details, usually of big property development corporations, are also clearly displayed.

\section{Collins Street}

567 Collins Street, an urban void of 30 years duration, is a relict from a period of urban restructuring following the decline of Melbourne's manufacturing industry in the mid-1970s. The name of the site indicates both the address and the title of a proposed development managed by the real estate development corporations APN Property Group and Colliers International. Evidently, the developer's interest lies in the profitable transformation and re-integration of the site into the productive urban landscape. As considerations for the development are largely driven by profit and efficiency, and are thus dependent on the economic market, the global financial crisis in 2008 further postponed work beginning on the development. In cases of long-term vacancy, the developer's interest lies mainly in securing the property to prevent dilapidation and value loss, clearing and fencing the property is standard practice. Approached by the Melbourne Void research team in 2011 with the idea to transform the site temporarily into an urban laboratory as part of ongoing research on urban voids, APN Property Group generously offered unrestricted and unconditional access to the site.

For one semester, the educational design research project provided landscape architecture students with a unique opportunity to actively work on-site in a dynamic urban context. Investigation into microclimatic conditions and their impact on vegetation through site mapping, interventions and 1:1 design experiments were conducted by 130 first year students from RMIT University. In this, the concept of an urban laboratory for landscape architecture emerged: students were invited to test landscape qualities such as climatic conditions and vegetation in a site specific plant experiment that they monitored over a period of 12 weeks. Simultaneously, a group of students from the University of Melbourne performed design interventions that captured the ephemeral nature of the site conditions. 
While the developer asked all activities to cease in late 2011 due to an imminent development plan, construction has still not begun and the site remains vacant until the present (November 2012).

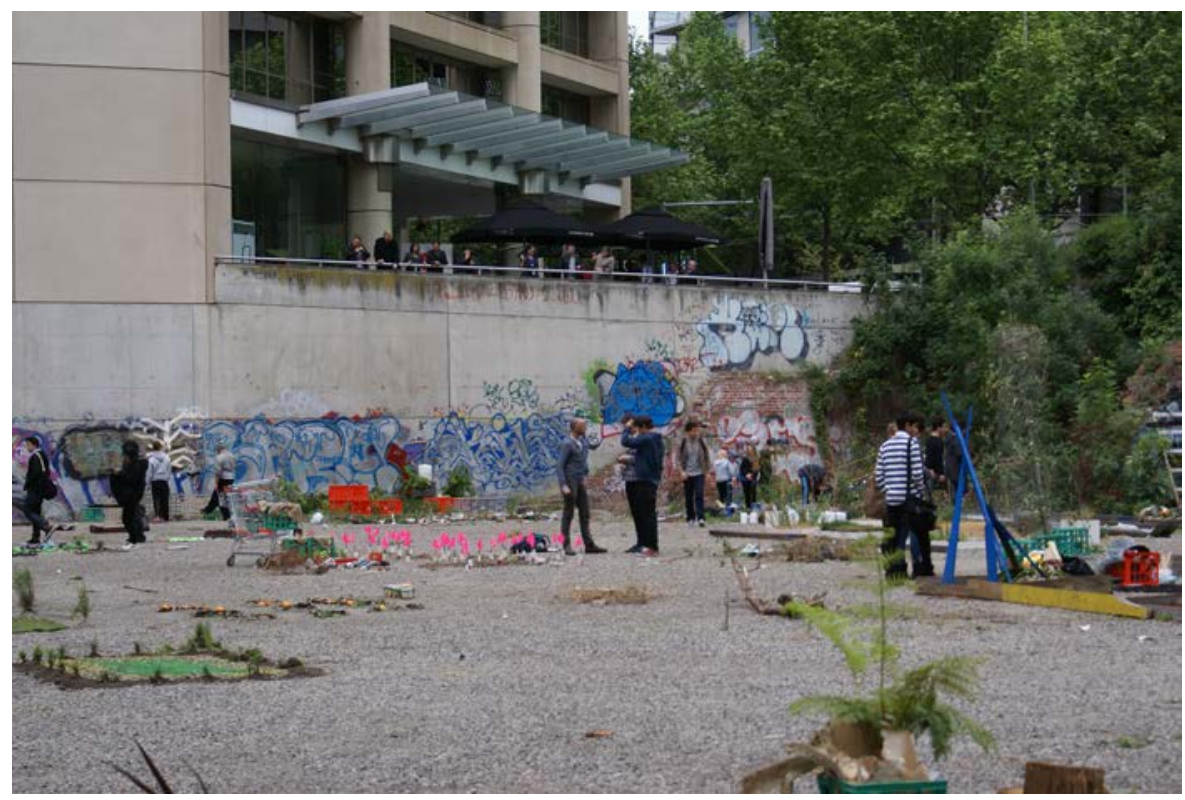

Figure 6. Urban Laboratory at 567 Collins Street, Melbourne, 2011.

Photography: The authors

\section{Transient Gardens, MoreArt Show}

Another observation of the Tokyo conditions that inspired a translation into the Melbourne context was the exploration of the distinct material nature of vacant sites. During the mapping process in Tokyo, we discovered a large number of plots that remained undisturbed by human interference for many years, and which consequently formed an impressive habitat for plants, birds, insects and small mammals. In these instances the value of the undisturbed and the forgotten becomes evident, providing an opportunity to speculate about the capacity of remnant vegetation on vacant sites to contribute to the larger urban ecosystem.

The Transient Gardens installation gave us the unique possibility to explore these issues as part of the MoreArt Show 2011. Initiated and curated by Moreland City Council in cooperation with VicTrack, the MoreArt Show is an example of a temporary activation strategy for urban voids. For a period of four weeks, the free public exhibition seeks creative responses to numerous vacant spaces in the municipality. Providing both indoor and outdoor sites along an urban railway corridor, the curators invited artists and designers to engage with the ephemeral and temporary qualities of the sites that respond to Moreland's unique urban 
landscape and character. The creative works were largely sculptural and installation-based, as the sites remained closed to public access and no direct interaction with the site was possible.

Transient Gardens worked with an outdoor site and carefully transformed the existing wild growing vegetation into a striking show of the other nature of urban spaces. The design response was site-specific and interactive to bikepath users by manipulating the existing vegetation on site. We saw the project as a chance to highlight the ephemeral nature and beauty of urban ecologies. Recognition of the biodiversity of urban voids became a focus point for the project. French landscape architect Gilles Clément states that 'Biodiversity is dependent on us, and we are dependent on it. Such diversity not only needs to be safeguarded, it needs to be established and looked after' (Mathieu 2011). Taking this as a starting point, Transient Gardens introduced small gestures that celebrated the biodiversity of urban voids. We identified the existing plant species on site and provided each plant with a pseudonym and a short piece of writing that questioned the notion and classification of weeds. The plants and their new identity were then displayed in a portrait gallery on the fence surrounding the site.
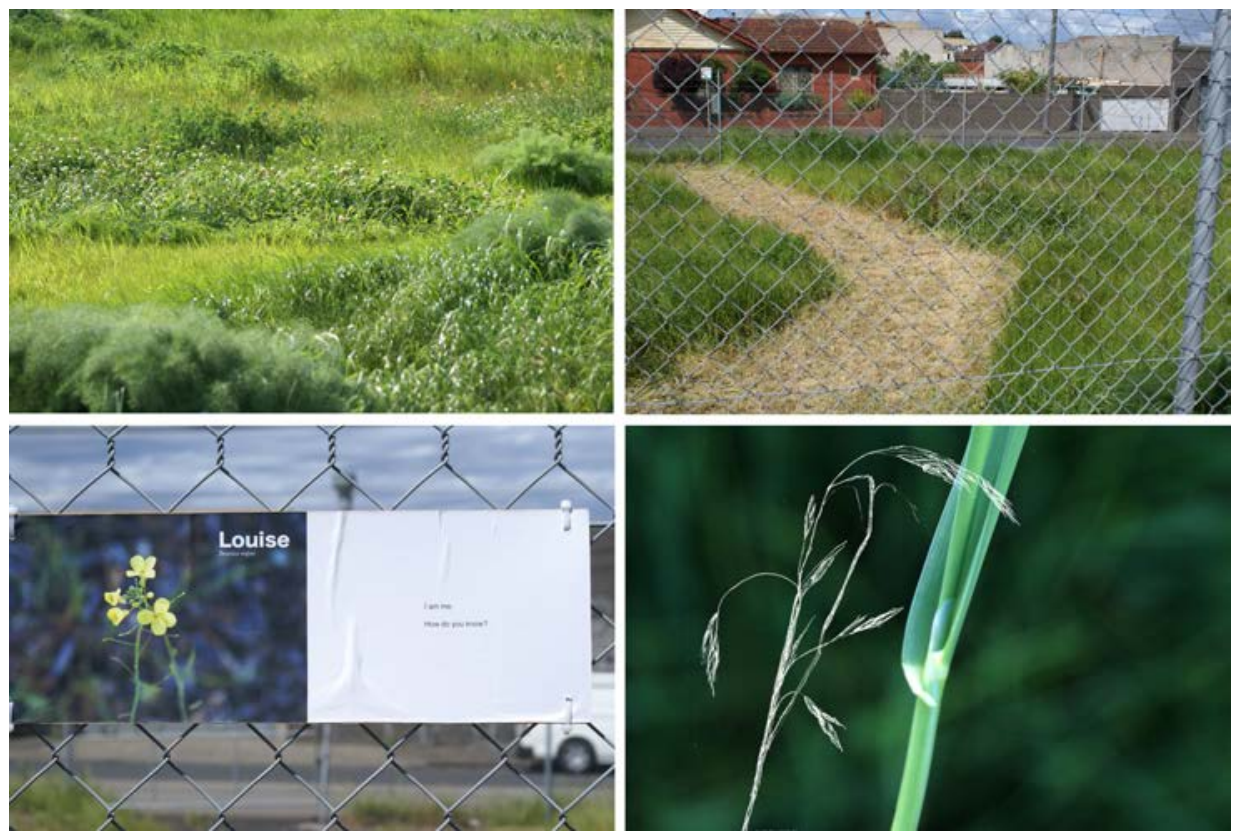

Figure 7. Transient Gardens, VicTrack Railway corridor at Moreland Station, 2011.

Photography: The authors

Through this action, the 27 identified plants offered a striking contrast to the low biodiversity in planned and highly maintained parks and public gardens in Melbourne. Clément discusses weeds and remnant vegetation in the idea of jardin planétaire: 'the planetary garden, a non-defined, leftover space that 
allows for the existence of weeds and becomes a biological time capsule for the future' (Clément \& Rahm 2006: 92). This biological time capsule often maintains a greater biodiversity than the low maintenance, maximum efficiency green spaces provided by municipalities. If we consider the small pockets of urban voids that have been undisturbed by human interference for years or, in rare cases, decades, the potential of this biological time capsule manifests itself in the vegetation. Considering the effects of urban vegetation on carbon dioxide absorption, air quality, and water filter capacity, the Transient Garden project subsequently raised critical questions about the currently predominant practice of clearing remnant vegetation from urban vacant sites.

\section{Doubt and Reward}

Reflecting on our practice, further questions emerge, together with a sense of both doubt and reward, failure and success. By way of a conclusion, we unpack these and consider further the potential of a context-driven design practice in landscape architecture in relation to the idea of a dynamic urbanism:

- What is the role of the designer in the context of urban voids?

- In our practice the role has shifted from designing for a site, to reading a complex problem and using the site to communicate and test this problem.

We have come to an understanding that urban voids offer multiple readings that might include activation strategies on one end of the spectrum and passive eco-functions on the other. This requires the designer's role to be equally multifaceted. Consequently, a clear position on scale and scope of the project is required when working with urban voids. Are they seen as testing ground? Are they being designed specifically? In positioning a practice around these types of questions it is possible to define the role of the designer.

In merging ownership with design intent, as demonstrated by ONDI, the role of creative action is passed to the public, which redefines spatial uses through its own practice.

\section{What drives the practice and underlying concepts?}

Questioning the role of the designer leads to more pragmatic issues: How can a practice be developed that is flexible, but formal enough to respond to the requirements of an owner and a site in transition? How does formal design practice respond to temporal and monetary limitations? How does the practice respond to an absence of clients and a design brief?

The reward of working with non-commissioned projects lies in discovery and communication of distinct and experimental approaches. In working with the site as a laboratory, a free experimentation is possible that, in turn, allows for new and site-specific insights to emerge, informing a more theoretical reading of the site processes in relation to commissioned design practice. Through this 
we see the need to define an idea of dynamic urbanism that allows for a holistic view on processes of growth and decay, renewal and abandonment on an urban scale in the context of design practice.

\title{
What is the role of the site?
}

Void spaces may function as small-scale microhabitats, buffers for urban heat island phenomena and mitigation of other extreme climate events. Thus, it can be suggested that through vegetation, void spaces offer the capacity to contribute to sustainable urban regeneration and to the provision of ecosystem functions on a larger urban scale. So, how can the opportunistic nature of urban voids be used to inspire uses that lie outside of cycles of consumption and offer up engagement with types of urban natures?

Urban micro natures can serve to form a landscape pattern that maps human interference - or rather - non-interference. Weeds, uncontrolled and unproductive invaders are subtly defining a pattern of urban ecosystems.

The reading of these patterns leads to doubting an approach that seeks to activate the sites - to fill the sites with program, i.e., design. A non-interference strategy contradicts an ambition of uncovering potential through activation, yet forms a key step in looking at voids: it is not what they do, but how they are, that informs how we read and think through them. - This is both rewarding and challenging.

\begin{abstract}
Marieluise Jonas is currently a lecturer and program director in landscape architecture at the School of Architecture and Design at RMIT University, Melbourne, and holds a PhD form the University of Tokyo, where she researched the practice and tradition of informal use of space in Japanese urban conditions.
\end{abstract}

Heike Rahmann is a landscape architect and lecturer at the University of Melbourne, Faculty of Architecture, Building and Planning. From 2004 she was a research fellow at the University of Tokyo, Japan, where she obtained a doctorate from the Department of Architecture.

\section{References}

AECOM, 2010, Asia Beyond Growth, London: Thames \& Hudson.

Australian Bureau of Statistics, Population Clock, viewed July 2011, http://www. abs.gov.au

Berger, A. 2006, Drosscape: Wasting land in urban America, New York: Princeton Architectural Press. 
Burdett, R. \& Sudjic, D. (eds) 2007, The Endless City: The urban age project by the London School of Economics and Deutsche Bank's Alfred Herrhausen Society, London: Phaidon.

Clement, G. \& Rahm, P. 2006, Environ(ne)ment: Approaches for tomorrow, Paris: Skira.

Gissen, D. 2009, Subnatures: Architecture's other environments, New York: Princeton Architectural Press.

Lévesque, L. 2002, 'The "terrain vague" as material - some observations', viewed Jan. 2011, http://www.amarrages.com/textes_terrain.html

Mathieu, G. 2011, 'Gilles Clement illustrated by Marseille: the Third Landscape of the L2'. Latent Marseilles, viewed July 2012, http://latentmarseille.tumblr. com/post/3385832983/gilles-clement-illustrated-by-marseille-the-third

Müller, H., Schmitt, G. \& Selle, K. (eds) 2003, Stadtentwicklung Rückwärts! Brachen als Chance? Aachen, Dortmund, Hannover: Dortmunder Vertrieb für Bau- und Planungsliteratur.

Oswalt, P. 2005, Shrinking Cities - Volume 1: International research, OstfildernRuit: Hatje Cantz.

Overmeyer, K. 2002, 'Schrumpfung als Experiment'. Garten + Landschaft.

- - (ed.) 2007, Urban Pioneers, Berlin: Senatsverwaltung für Stadtentwicklung. Jovis Verlag.

Solà-Morales, I. (1995). 'Terrain Vague'. in C. Davidson (ed.) Anyplace, Cambridge: MIT Press.

Tokyo Metropolitan Government Bureau Of General Affairs, Statistic Division Management and Coordination Section, 2007. Tokyo Statistical Yearbook 2007, 1 Land and Climate, Tokyo Metropolitan Government.

Victorian Environmental Assessment Council (VEAC), 2010, Discussion Paper Part C - Public land in metropolitan Melbourne, viewed 7 Feb. 2011, http:// www.veac.vic.gov.au/investigation/metropolitan-melbourne-investigation/ reports 